\title{
Cohnella cholangitidis sp. nov., a novel species of the genus Cohnella isolated from a clinical specimen in Korea
}

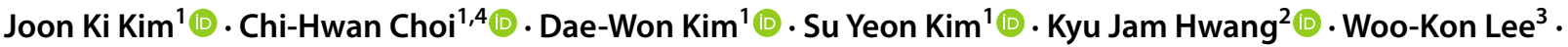 \\ Min Kyoung $\mathrm{Shin}^{3} \cdot$ Myunghwan Jung $^{3} \cdot$ Young Sill Choi $^{1}$ (])
}

Received: 18 August 2020 / Revised: 2 September 2021 / Accepted: 3 September 2021 / Published online: 25 September 2021

(c) The Author(s) 2021

\begin{abstract}
A Gram-positive, aerobic, rod-shaped bacterium, designated as strain $1605-214^{\mathrm{T}}$, was isolated from the blood sample of a patient with cholangitis. Based on its 16S rRNA gene sequence, the strain $1605-214^{\mathrm{T}}$ belonged to the genus Cohnella and exhibited 97.9\% sequence identity with Cohnella luojiensis DSM $24270^{\mathrm{T}}$ (GQ214052). DNA-DNA hybridization, digital DNA-DNA hybridization, and average nucleotide identity values between the two species were $23 \% \pm 1.9,21.1 \%$, and $77.2 \%$, respectively. The cellular fatty acids of strain $1605-214^{\mathrm{T}}$ were mainly comprised of anteiso- $\mathrm{C}_{15: 0}(36.1 \%)$, iso- $\mathrm{C}_{16: 0}(16.5 \%)$, and $\mathrm{C}_{16: 0}(15.1 \%)$. The predominant quinone was menaquinone-7; predominant polar lipids were diphosphatidylglycerol, phosphatidylethanolamine, and aminophospholipid-1. The cell wall peptidoglycan of strain $1605-214^{\mathrm{T}}$ contained mesodiaminopimelic acid. DNA G + C content of strain $1605-214^{\mathrm{T}}$ was $50.6 \mathrm{~mol} \% .5187$ genes out of a total of $5413(94.6 \%)$ were assigned putative functions using eggNOG v5.0. Based on genotypic characteristics and genomic sequence analysis results, strain $1605-214^{\mathrm{T}}$ was confirmed to represent a novel species of genus Cohnella, for which the name Cohnella cholangitidis sp. nov., was proposed.
\end{abstract}

Keywords Cohnella cholangitidis $\cdot$ Novel species $\cdot$ Complete genome $\cdot$ Human blood $\cdot$ Taxonomy

\section{Abbreviations \\ BAP Blood agar plate \\ ANI Average nucleotide identity \\ DDH DNA-DNA hybridization \\ dDDH Digital DNA-DNA hybridization}

Communicated by Erko Stackebrandt

Joon Ki Kim and Chi-Hwan Choi contributed equally to this work.

Young Sill Choi

yschoi83@korea.kr

1 Division of Pathogen Resource Management, Center for Public Vaccine Development Support, National Institute of Health, Korea Disease Control and Prevention Agency (KDCA), Cheongju, Republic of Korea

2 Division of Bacterial Diseases, Bureau of Infectious Diseases Diagnosis Control, Korea Disease Control and Prevention Agency (KDCA), Cheongju, Republic of Korea

3 Department of Microbiology, School of Medicine, Gyeongsang National University, Jinju, Republic of Korea

4 Present Address: Division of High-Risk Pathogens, Korea Disease Control and Prevention Agency (KDCA), Cheongju, Republic of Korea
AGIOS Average of genomic identity of orthologous gene sequence

COG Cluster of orthologous groups

\section{Introduction}

The first species of the genus Cohnella was described as Cohnella thermotolerans in a report by Kämpfer et al (2006). Currently, the genus Cohnella comprises 37 species (LPSN: http://www.bacterio.net), including six that have not been validated. Most members of Cohnella were isolated from various environments such as soil (Cai et al. 2010; Kim et al. 2010, 2011), plants (Garcia-Fraile et al. 2008), water (Shiratori et al. 2010), and industrial materials (Kämpfer et al. 2006). Cohnella cellulosilytica (Khianngam et al. 2012) and Cohnella faecalis (Zhu et al. 2019) were isolated from animal excrements. Cohnella hongkongensis (Kämpfer et al. 2006) and Cohnella massiliensis (Abou Abdallah et al. 2019) were isolated from clinical samples (Table $S 1$ ). In the present study, we have described strain $1605-214^{\mathrm{T}}$ as a novel species of the genus Cohnella. To our knowledge, this is the 
first case in which a strain has been isolated from the blood culture of a cholangitis patient in South Korea.

\section{Materials and methods}

\section{Strain isolation and identification}

Strain $1605-214^{\mathrm{T}}$ was isolated from the blood culture of a cholangitis patient at Gyeongsang National University Hospital in Jinju, Gyeongsangnam-do, South Korea $\left(35^{\circ} 10^{\prime}\right.$ $\left.35.5^{\prime \prime} \mathrm{N}, 128^{\circ} 05^{\prime} 44.2^{\prime \prime} \mathrm{E}\right)$. The strain was grown on a blood agar plate (BAP) (KisanBio, Korea) at $30{ }^{\circ} \mathrm{C}$ for $48 \mathrm{~h}$ and stored at $-70{ }^{\circ} \mathrm{C}$ in $10 \%$ glycerol. Initial attempts of identification were made using matrix-assisted laser desorption/ ionization-time-of-flight mass spectrometry (MALDI-TOF MS) with MALDI Biotyper software (Bruker Daltonik, Germany). The experiment was performed using $C$. luojiensis DSM $24270^{\mathrm{T}}$, C. suwonensis DSM $25950^{\mathrm{T}}$, and C. yongneupensis DSM $18998^{\mathrm{T}}$ as reference strains for comparative analysis of species characteristics.

The 16S rRNA gene sequence similarity was calculated by comparing its sequence with those on the EzTaxon server (http://www.eztaxon.org/) (Chun et al. 2007). 16S rRNA gene sequencing was performed using universal primers 27F (3' -AGAGTTTGATCMTGGCTCAG- 5') and 1492R (5' -TACGGYTACCTTGTTACGACTT-3') (Lane 1991).

\section{Phenotypic, morphological, and biochemical characterization}

Gram staining was performed using Gram Stain Kits (BD), and a catalase test was performed by adding $3 \%$ hydrogen peroxide solution to bacteria smeared on slides. The growth conditions for strain $1605-214^{\mathrm{T}}$ were determined at different $\mathrm{pH}$ values (4-10, at $\mathrm{pH}$ intervals of 0.5 unit) on BAP. For analysis of its biochemical and enzymatic characteristics, VITEK 2 GP (bioMérieux, France) was used according to the manufacturer's instructions.

To analyze its isoprenoid quinones, the cell biomass of strain $1605-214^{\mathrm{T}}$ was obtained from cultures grown on BAP for 2 days at $30^{\circ} \mathrm{C}$. Quinones were extracted using the chloroform/methanol method [(C:M, 2:1, v/v)]. The extracted quinones were vacuum-evaporated and re-extracted using $\mathrm{n}$-hexane-water $(1: 1, \mathrm{v} / \mathrm{v})$. The purified quinones were analyzed using a reverse-phase HPLC system (Younglin, Korea), as described by Hiraishi et al. (1992).

The polar lipid composition of strain $1605-214^{\mathrm{T}}$ was determined as described previously (Minnikin et al. 1980). The polar lipid composition was analyzed by two-dimensional thin-layer chromatography (2D-TLC) on TLC Kiesel gel 60F254 (Merck, Germany) plates $(10 \times 10 \mathrm{~cm})$.

The cellular fatty acid composition of the isolated strain was analyzed according to Miller's method (Miller 1982). Agilent Technologies 6890 Gas Chromatography was performed to analyze the prepared samples, and an A30 $\mathrm{m} \times 0.320 \mathrm{~mm} \times 0.25 \mu \mathrm{m}$ crosslinked methyl siloxane column (HP-1) was used as a separation column. The profile was analyzed using Sherlock MIS Software. Peak identification, retention time, peak area, and area ratio were determined by comparison with the standard calibration solution.

The diaminopimelic acid in the cell wall was analyzed using a previously described method (Hasegawa et al. 1983).

DNA-DNA hybridization was performed using the fluorometric microwell method (Ezaki et al. 1989).

\section{Genomic DNA preparation and genome sequencing}

Genomic DNA was extracted by digestion of the bacteria with proteinase $\mathrm{K}$ in $10 \%$ SDS, followed by purification using the phenol extraction and ethanol precipitation methods. The primary sequencing library was prepared according to the protocol of the SMRTbell Template Prep Kit 1.0 (Pacific Biosciences, USA). The secondary sequencing library was prepared according to the protocol of the Ion Xpress Plus Fragment Library kit (Thermo Fisher Scientific, USA). The genome was sequenced using PacBio RS II (Pacific Biosciences, USA) and Ion S5 (Thermo Fisher Scientific, USA) sequencing platforms.

\section{Genome assembly}

SPAdes Genome Assembler (v3.1) was adopted for de novo assembly sequence reads generated by NGS platforms PacBio RS II and Ion S5, and produced contigs and scaffold sequences. SSPACE program was used for scaffolding contigs and scaffold sequences, and the remaining sequencing errors including gaps and low-quality region were corrected using Proovread (v2.14.0).

\section{Genome annotation}

The genome of strain $1605-214^{\mathrm{T}}$ was initially annotated using the PROKKA (Seemann 2014) software package. The NCBI Prokaryotic Genome Annotation Pipeline (PGAP) (Tatusova et al. 2016) software package was used to generate the final annotation. The predicted protein sequences were classified into functional groups in Clusters of Orthologous Groups (COG) using eggNOG 5.0 (Huerta-Cepas et al. 
2019). The resistance genes and virulence factors were identified using AMRFinderPlus (Feldgarden et al. 2019) and VFdb (Liu et al. 2018), respectively.

\section{S rRNA phylogenetic tree}

An initial genomic distance calculation was conducted by searching for the genetically closest strains in EzTaxon Server (Chun et al. 2007) and Type Strain Genome Server (TYGS) (Meier-Kolthoff and Göker 2019). The 16S rRNA sequences of 37 type strains belonging to the Cohnella genus were downloaded from the list of prokaryotic names with standing in nomenclature (LPSN) (Parte 2018). The multiple sequence alignment was processed using MAFFT (Katoh and Standley 2013). Phylogenetic trees were constructed with 1000 bootstrap replicates using the neighborjoining (NJ) method by MEGA7 (Kumar et al. 2016) and the maximum-likelihood (ML) method by RAxML (Stamatakis 2014). Figtree software was used to visualize the trees (http://tree.bio.ed.ac.uk/software/figtree).

\section{Genomic sequence similarity comparison}

Genomic sequence similarity comparison was conducted using the available genomes of the five closest Cohnella species. OrthoANI (Lee et al. 2016) and digital DNA-DNA hybridization (dDDH) (Meier-Kolthoff et al. 2013) were used to compare genome similarities. To calculate the average genomic identity of orthologous gene sequences (AGIOS) (Ramasamy et al. 2014) between genomes, the sets of orthologous proteins were first obtained using BLASTP, with the reciprocal-best-BLAST-hits $(\mathrm{RBH})$ approach (minimal coverage of $50 \%$, amino acid identity of $30 \%$ ). The mean percentages of nucleotide sequence identity between the orthologous genes were then calculated.

\section{Strain and sequence deposition}

Strain $1605-214^{\mathrm{T}}$ has been deposited in two microbial culture collections: the National Culture Collection for
Fig. 1 Phylogenetic tree of strain $1605-214^{\mathrm{T}}$ and closely related species based on $16 \mathrm{~S}$ rRNA gene sequences. Tree was constructed using neighborjoining methods. Numbers at branch nodes are percentages of 1000 bootstrap replications. Only values $\geq 60 \%$ are shown. Bar under the trees indicates the nucleotide substitution rate $(0.005=1 / 10 \mathrm{E}-3)$

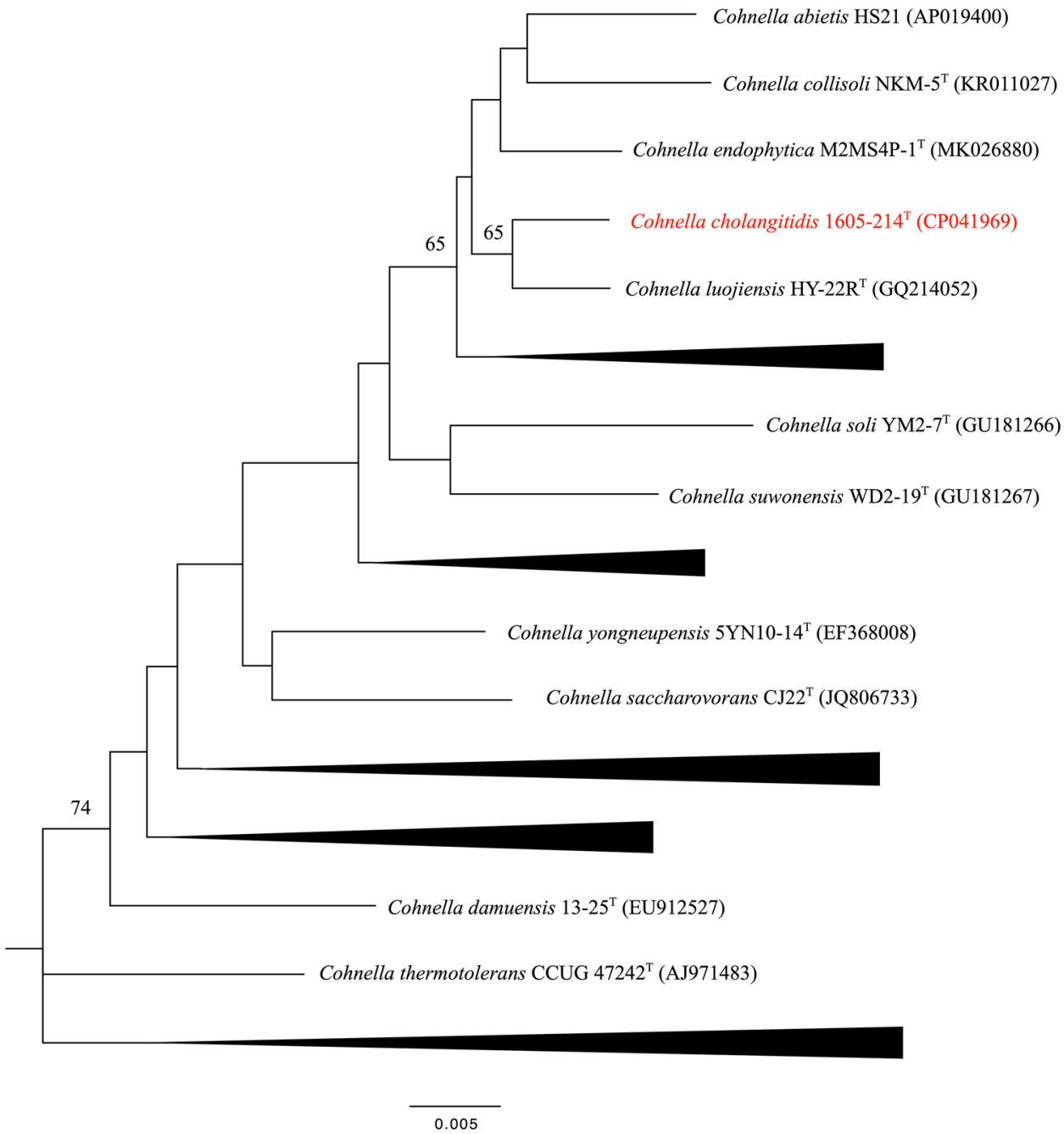


Pathogens in South Korea (NCCP), under accession number NCCP 16833, and the German collection of microorganisms (Deutsche Sammlung von Mikroorganismen und Zellkulturen GmbH in Germany, DSMZ), under the accession number DSM 112742.

The complete genomic sequences of strain $1605-214^{\mathrm{T}}$ have been deposited at DDBJ/ENA/GenBank under the accession number CP041969.

\section{Results and discussion}

\section{Phylogenetic affiliation}

Three attempts to identify strain $1605-214^{\mathrm{T}}$ by MALDITOF MS failed. Phylogenetic analysis, based on 16S rRNA gene sequences (Table S2) revealed that strain 1605-214 ${ }^{\mathrm{T}}$ belonged to the genus Cohnella and was closely related to Cohnella luojiensis DSM $24270^{\mathrm{T}}$ (97.9\%) (Fig. 1, Figure S1).

\section{Phenotype}

The optimal conditions of strain $1605-214^{\mathrm{T}}$ for growth were a temperature of $30{ }^{\circ} \mathrm{C}$ and a pH of 7 (Table 1). Based on VITEK 2 GP results, all four Cohnella spp. strains were positive for beta-galactosidase, beta galactopyranosidase, and alpha-galactosidase. In addition, strain $1605-214^{\mathrm{T}}$ was positive for alpha-glucosidase and negative for D-trehalose, whereas Cohnella luojiensis, which is considered a genetically close species, was negative and positive, respectively, for the above-mentioned enzymes. The major lipid classes of strain $1605-214^{\mathrm{T}}$ were identified as diphosphatidylglycerol (DPG), phosphatidylethanolamine (PE), and aminophospholipid-1 (APL1). The major quinone present in the strain was identified as MK-7. The cell wall peptidoglycan of strain $1605-214^{\mathrm{T}}$ contained meso-diaminopimelic acid. The $\mathrm{G}+\mathrm{C}$ content of strain $1605-214^{\mathrm{T}}$ was $50.6 \mathrm{~mol} \%$, and the major fatty acids were anteiso- $\mathrm{C}_{15: 0}(36.1 \%)$, iso- $\mathrm{C}_{16: 0}(16.5 \%)$, and $\mathrm{C}_{16: 0}$ (15.1\%) (Table 2). The relatedness of DNA between strain $1605-214^{\mathrm{T}}$ and C. luojiensis DSM $24270^{\mathrm{T}}$ was
Table 1 Comparison of characteristics of strain $1605-$ $214^{\mathrm{T}}$ and related type strains of Cohnella species

\begin{tabular}{lllll}
\hline Characteristic & 1 & 2 & 3 & 4 \\
\hline Gram stain & + & + & + & + \\
Catalase & + & + & + & + \\
Motility & - & - & - & - \\
Temperature range $\left({ }^{\circ} \mathrm{C}\right)$ & $15-42$ & $15-37$ & $15-37$ & $10-37$ \\
Optimal pH for growth & $6-8$ & $6-8$ & $6-8.5$ & $5.5-8.5$ \\
Polar lipids & DPG, PE, APL1 & DPG, PG, PE, PL1 & DPG, PG, PE, & DPG, PG, \\
& & & APL4, APL5 & PE, APL2, \\
& & & mPL3 & meso-DAP \\
Diaminopimelic (DAP) acid & meso-DAP & meso-DAP & MK-7 & MK-7 \\
Quinones & MK-7 & MK-7 & 54.4 & 51.4 \\
G+C content (mol\%) & 50.6 & 48.3 & + & + \\
Beta-galactosidase & + & + & - & - \\
Alpha-glucosidase & + & - & + & + \\
Beta galactopyranosidase & + & + & + & + \\
Alpha-galactosidase & + & + & - & - \\
D-trehalose & - & + & & \\
\hline
\end{tabular}

All data are from the present study. +, positive; -, negative; w, weakly positive

Negative for all 4 strains: D-amygdalin, Phosphatidylinositol phospholipase C, D-xylose, Arginine dihydrolase 1, Ala-Phe-Pro arylamidase, Cyclodextrin, L-Aspartate arylamidase, Alpha-mannosidase, Phosphatase, Leucine arylamidase, L-Proline arylamidase, Beta glucuronidase, L-pyrrolidonyl-arylamidase, Beta glucuronidase, Alanine arylamidase, Tyrosine arylamidase, D-sorbitol, Polymyxin B resistance, D-galactose, D-ribose, L-Lactate alkalinization, Lactose, N-Acetyl-D-glucosamine, D-maltose, Bacitracin resistance, Novobiocin resistance, Growth In 6.5\% NaCl, D-mannitol, D-mannose, Methyl-B-D-glucopyranoside, Pullulan, D-raffinose, O/129 resistance (Comp.Vibrio.), Salicin, Saccharose/Sucrose, Arginine dihydrolase 2, Optochin resistance

1-C. cholangitidis $1605-214^{\mathrm{T}} ; 2-$ C. luojiensis DSM $24270^{\mathrm{T}}$; 3-C. suwonensis DSM 25950 $;$; - C. yongneupensis DSM $18998^{\mathrm{T}}$ 
Table 2 Cellular fatty acid content (\%) of strain $1605-214^{\mathrm{T}}$ and C. luojiensis DSM $24270^{\mathrm{T}}$, C. suwonensis DSM $25950^{\mathrm{T}}$, and C. yongneupensis DSM $18998^{\mathrm{T}}$

\begin{tabular}{|c|c|c|c|c|}
\hline Fatty acid & 1 & 2 & 3 & 4 \\
\hline 10:00 & 0.1 & - & - & - \\
\hline $12: 0$ iso & - & - & - & 0.3 \\
\hline $12: 00$ & 0.3 & 1.6 & 0.6 & 0.6 \\
\hline $13: 0$ iso & 0.2 & - & - & - \\
\hline 13:0 anteiso & 0.9 & - & 1.5 & 1.5 \\
\hline $14: 0$ iso & 2.5 & 2.1 & 4.2 & 2.1 \\
\hline $14: 00$ & 1.3 & 1.0 & 1.2 & 1.5 \\
\hline $15: 0$ iso & 4.8 & 9.0 & 6 & 2.2 \\
\hline $15: 0$ anteiso & 36.1 & 51.2 & 51.9 & 45.1 \\
\hline 16:1 w7c alcohol & 0.5 & 2.1 & - & - \\
\hline $16: 00$ & 15.1 & 4.9 & 7.7 & 14.0 \\
\hline $16: 0$ iso & 16.5 & 11.0 & 20.5 & 23.6 \\
\hline $16: 1 \mathrm{w} 11 \mathrm{c}$ & 0.3 & 1.9 & - & - \\
\hline $16: 1 \mathrm{w} 7 \mathrm{c} / 16: 1 \mathrm{w} 6 \mathrm{c}$ & 0.2 & - & - & - \\
\hline $17: 1$ iso $w 10 \mathrm{c}$ & - & 1.4 & - & - \\
\hline $17: 0$ iso & 4.2 & 4.3 & 1.9 & 0.9 \\
\hline 17:0 anteiso & 5.3 & 8.2 & 4.5 & 6.7 \\
\hline $17: 00$ & 0.9 & - & - & - \\
\hline $18: 0$ iso & 0.2 & - & - & - \\
\hline 18:00 & - & - & - & 0.8 \\
\hline $18: 2 \mathrm{w} 6,9 \mathrm{c} / 18: 0$ ante & 0.6 & - & - & - \\
\hline $18: 1 \mathrm{w} 9 \mathrm{c}$ & 4.9 & - & - & 0.9 \\
\hline $18: 1 \mathrm{w} 7 \mathrm{c}$ & 0.3 & - & - & - \\
\hline $18: 1$ w6c & 0.5 & - & - & - \\
\hline 18:00 & 4.3 & - & - & - \\
\hline $16: 1 \mathrm{w} 7 \mathrm{c} / 16: 1 \mathrm{w} 6 \mathrm{c}$ & 0.2 & - & - & - \\
\hline $17: 1$ iso $\mathrm{I} /$ anteiso $\mathrm{B}$ & - & 1.3 & - & - \\
\hline $18: 2 \mathrm{w} 6,9 \mathrm{c} / 18: 0$ ante & 0.5 & - & - & - \\
\hline $18: 1 \mathrm{w} 7 \mathrm{c}$ or $18: 1 \mathrm{w} 6 \mathrm{c}$ & 0.8 & - & - & - \\
\hline
\end{tabular}

All data are from the present study. - Not detected

1-C. cholangitidis $1605-214^{\mathrm{T}} ; 2$ - C. luojiensis DSM $24270^{\mathrm{T}} ; 3$ - C. suwonensis DSM $25950^{\mathrm{T}}$; 4 - C. yongneupensis DSM $18998^{\mathrm{T}}$

*Summed features represent groups of two fatty acids that could not be separated by GLC using the MIDI system

Table $3 \mathrm{G}+\mathrm{C}$ content, digital DNA-DNA hybridization (dDDH), average nucleotide identity (ANI), and 16S rRNA sequence identity of the genome sequences of $C$. cholangitidis $1605-214^{\mathrm{T}}$ and the four closest strains

\begin{tabular}{|c|c|c|c|c|c|c|c|c|}
\hline Species & Strain & GenBank accession & $\begin{array}{l}\text { Genome assembly } \\
\text { level (contig no.) }\end{array}$ & $\begin{array}{l}\text { Sequence } \\
\text { length } \\
(\mathrm{Mbp})\end{array}$ & $\begin{array}{l}\mathrm{G}+\mathrm{C} \\
\text { content } \\
(\%)\end{array}$ & $\mathrm{dDDH}(\%)$ & ANI $(\%)$ & 16S rRNA (\%) \\
\hline C. cholangitidis & $1605-214^{\mathrm{T}}$ & СР041969 & Complete (1) & 6.4 & 51.2 & - & - & - \\
\hline C. luojiensis & $\mathrm{HY}-22^{\mathrm{T}}$ & NZ_SOMN00000000 & Draft (115) & 5.04 & 49.9 & 21.1 & 77.2 & 97.9 \\
\hline C. abietis & $\mathrm{HS}-21^{\mathrm{T}}$ & AP019400 & Complete (1) & 7.05 & 44.8 & 19.5 & 73.6 & 97.6 \\
\hline C. endophytica & M2MS4P- $1^{\mathrm{T}}$ & NZ_RBZM00000000 & Draft (32) & 6.26 & 51.5 & 20.3 & 75.4 & 97.4 \\
\hline C. lupini & RLAHU4B $^{\mathrm{T}}$ & NZ_QRDY00000000 & Draft (65) & 6.34 & 50.7 & 20.6 & 76.1 & 97.2 \\
\hline
\end{tabular}




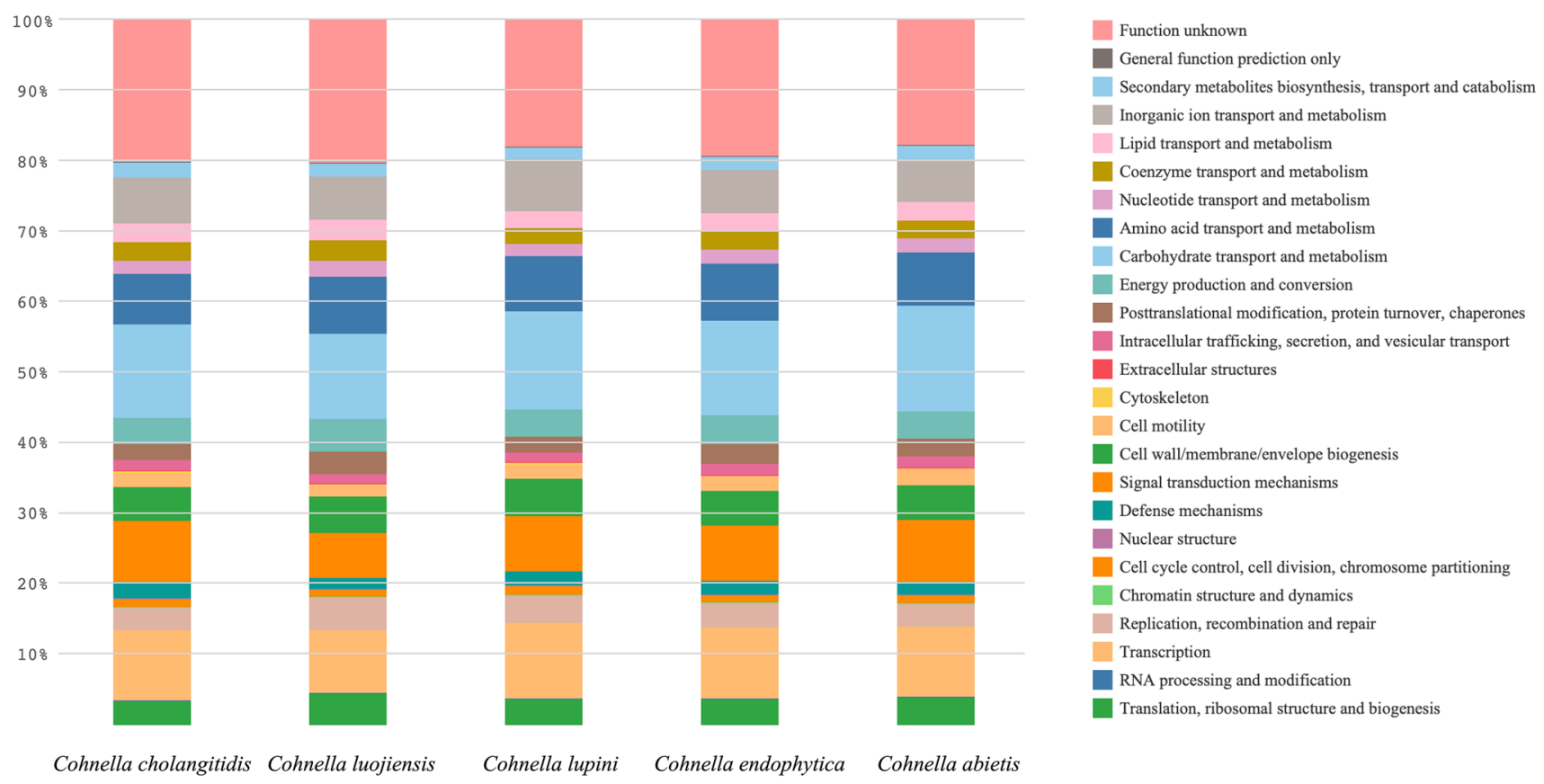

Fig. 2 Functional COG distribution of the predicted genes in genomes. Gene components between the four closest species of genomes showed a similar composition of functional COG distribution

Table 4 The number of shared orthologous genes between the genomes of four closely related strains (upper diagonal numbers), the average genomic identity of orthologous gene sequences correspond- ing to orthologous proteins shared between the genomes (lower diagonal numbers), and number of proteins per genome (principal diagonal elements; bold numbers)

\begin{tabular}{|c|c|c|c|c|c|}
\hline & $1605-214^{\mathrm{T}}$ & $\mathrm{HY}-22^{\mathrm{T}}$ & $\mathrm{HS}-21^{\mathrm{T}}$ & M2MS4P-1 ${ }^{\mathrm{T}}$ & RLAHU4B $^{\mathrm{T}}$ \\
\hline C. cholangitidis $1605-214^{\mathrm{T}}$ & 5481 & 3853 & 4163 & 4084 & 4127 \\
\hline C. luojiensis $\mathrm{HY}-22^{\mathrm{T}}$ & 48.9 & 4737 & 3979 & 3950 & 3851 \\
\hline C. abietis HS- $21^{\mathrm{T}}$ & 48.5 & 64.7 & 6203 & 4380 & 4341 \\
\hline C. endophytica M2MS4P- $1^{\mathrm{T}}$ & 48.9 & 66.8 & 64.2 & 5335 & 4199 \\
\hline C. lupini RLAHU4B ${ }^{\mathrm{T}}$ & 49.0 & 71.2 & 64.4 & 67.7 & 5608 \\
\hline
\end{tabular}

$23.0 \% \pm 1.9$. Based on phenotypic and genotypic distinctness and DNA-DNA hybridization results, strain $1605-214^{\mathrm{T}}$ was confirmed to be a novel pathogenic species similar to C. luojiensis.

\section{Genome properties}

The complete genome of strain $1605-214^{\mathrm{T}}$ is $6,408,853 \mathrm{bp}$ in length with a GC content of $51.2 \%$. Out of the 5867 predicted genes, 5481 genes code for proteins and 95 code for RNA ( 8 genes are 5S rRNA genes; 8 genes are 16S rRNA; 8 genes are 23S rRNA genes; 67 genes are tRNA genes; 4 genes are ncRNAs genes) (Table S3). From the analysis of Clusters of Orthologous Groups of proteins (COGs), a total of 5,187 genes $(94.6 \%)$ were assigned putative functions (Table S4). The strain $1605-214^{\mathrm{T}}$ contained 896 genes (16.3\%) for information storage and processing, 1224 genes
(22.3\%) for cellular processes and signaling, and 2108 genes $(38.5 \%)$ for metabolism. An in silico search for the resistome of this strain revealed that the clbC gene (90.4\% identity) (Hansen et al. 2012) confers resistance to PhLOPSa (phenicol, lincosamide, oxazolidinone, pleuromutilin, and streptogramin A) antibiotics and was identified by NCBI AMRFinder program (Feldgarden et al. 2019). An in silico search for virulence factors revealed eight proteins with high identity percentages conferring potential pathogenicity. These proteins were LPS biosynthesis protein PseA-like (79.2\% identity), chaperonin GroEL (75.3\%), translation elongation factor Tu (73.6\%), UTP-glucose-1-phosphate uridylyltransferase gtaB (71.8\%), imidazole glycerol phosphate synthase subunit HisF (71.3\%), ATP-dependent Clp protease proteolytic subunit clpP (71.3\%), enolase eno (70.3\%), and glucose-1-phosphate thymidyl transferase $\mathrm{rmlA}(70.2 \%)$. 


\section{Comparison with genomes of other Cohnella species}

At the time of manuscript preparation, the $16 \mathrm{~S}$ rRNA sequences of the type strains were analyzed as mentioned above; however, a comparison at the whole-genome level was not possible. Therefore, the Cohnella cholangitidis $1605-214^{\mathrm{T}}$ was further compared to four type strains, including C. luojiensis (Table 3). The four strains were selected based on the results of the dDDH analysis from TYGS. Additionally, average nucleotide identity (ANI) analysis was also performed for the strains. The $\mathrm{dDDH}$ and ANI results for the assessed strains were, respectively, as follows: $C$. luojiensis $(21.1 \%, 77.2 \%)$, C. lupini $(20.6 \%, 76.1 \%), C$. endophytica $(20.3 \%, 75.4 \%)$, and C. abietis $(19.5 \%, 73.7 \%)$ (Table 3$)$. These dDDH $(<70 \%)$ and ANI $(<95 \%)$ values indicated that strain $1605-214^{\mathrm{T}}$ represents a species distinct from other Cohnella strains. The distribution of genes into COG categories was similar in the gnomes of five strains as shown in Fig. 2. Strain 1605-214 ${ }^{\mathrm{T}}$ shared 3853, 4127, 4163 , and 4084 orthologous genes with C. lupijiensis, C. lupini, $C$. abietis, $C$. endophytica, respectively (Table 4, upper diagonal numbers). The average genomic identity of orthologous gene sequence (AGIOS) ranged from $48.5 \%$ with C. abietis to $49.0 \%$ with $C$. luojiensis (Table 4 , lower diagonal numbers).

\section{Conclusion}

The phenotypic, morphological, and biochemical characterizations, genome perspectives, and comparative genome analyses suggested that strain $1605-214^{\mathrm{T}}$ represents a novel species of the genus Cohnella for which the name $C$. cholangitidis is proposed.

\section{Description of Cohnella cholangitidis sp. nov.}

Cohnella cholangitidis (chol.an.gi'ti.dis. N.L. gen. n. cholangitidis of cholangitis, derived from the disease of the patient from which this strain was isolated).

Gram-positive, rod-shaped, catalase-positive, oxidasepositive, and facultative anaerobic. Colonies are grayishwhite in color and $0.5 \mathrm{~mm}$ in size on BAP. The optimal growth conditions are $30{ }^{\circ} \mathrm{C}$ and $\mathrm{pH} 7$, although growth is also observed at $15-42{ }^{\circ} \mathrm{C}$ and $\mathrm{pH}$ 6-8. Positive for alphagalactosidase, beta-galactosidase, alpha-glucosidase, and beta-galactopyranosidase. The $\mathrm{G}+\mathrm{C}$ content is $50.6 \mathrm{~mol} \%$ and the major fatty acids are anteiso-C15:0 (36.1\%), isoC16:0 (16.5\%), and C16:0 (15.1\%). The major lipids are diphosphatidylglycerol (DPG), phosphatidylethanolamine (PE), and aminophospholipid-1 (APL1). The major quinone is MK-7. The cell wall contains meso-diaminopimelic acid.
Strain $1605-214^{\mathrm{T}}\left(=\mathrm{NCCP} 16833^{\mathrm{T}},=\right.$ DSM $\left.112742^{\mathrm{T}}\right)$ was isolated from a clinical specimen at the Gyeongsang National University Hospital in Jinju, Gyeongsangnam-do, South Korea.

Supplementary Information The online version contains supplementary material available at https://doi.org/10.1007/s00203-021-02565-3.

Acknowledgements This research was supported and funded by Korea National Institute of Health (2017-NG45004-00). We would like to thank Editage for English language editing.

Author contributions Conceptualization: JKK, C-HC; methodology: JKK, D-WK, C-HC; formal analysis and investigation: JKK, C-HC; writing-original draft of the manuscript: JKK, C-HC; writingreview and editing: D-WK, KJH, SYK, YSC; funding acquisition: $\mathrm{KJH}$, YSC; resources: W-KL, MKS, MJ; supervision: YSC.

Funding This research was supported and funded by Korea National Institute of Health (2017-NG45004-00).

Availability of data and materials All data generated or analyzed during this study are included in this published article and its Supplementary Information files. Additional data are available from the corresponding author upon request. Depositories: Strain 1605-214 has been deposited in the National Culture Collection for Pathogens in South Korea (NCCP), and Deutsche Sammlung von Mikroorganismen und Zellkulturen GmbH (DSMZ), under the accession number NCCP 16833-DSM 112742

Code availability Not applicable.

\section{Declarations}

Conflict of interest The authors declare that they have no conflict of interest.

Ethical approval Not applicable.

Consent to participate Not applicable.

Consent for publication Not applicable.

Open Access This article is licensed under a Creative Commons Attribution 4.0 International License, which permits use, sharing, adaptation, distribution and reproduction in any medium or format, as long as you give appropriate credit to the original author(s) and the source, provide a link to the Creative Commons licence, and indicate if changes were made. The images or other third party material in this article are included in the article's Creative Commons licence, unless indicated otherwise in a credit line to the material. If material is not included in the article's Creative Commons licence and your intended use is not permitted by statutory regulation or exceeds the permitted use, you will need to obtain permission directly from the copyright holder. To view a copy of this licence, visit http://creativecommons.org/licenses/by/4.0/.

\section{References}

Abou Abdallah R, Bou Khalil J, Andrieu C et al (2019) Draft genome and description of Cohnella massiliensis sp. nov. a new 
bacterial species isolated from the blood culture of a hemodialysis patient. Arch Microbiol 201:305-312. https://doi.org/10.1007/ s00203-018-1612-1

Cai F, Wang Y, Qi H, Dai J, Yu B, An H, Rahman E, Fang C (2010) Cohnella luojiensis sp. nov., isolated from soil of a Euphrates poplar forest. Int J Syst Evol Microbiol 60:1605-1608. https:// doi.org/10.1099/ijs.0.016790-0

Chun J, Lee J-H, Jung Y et al (2007) EzTaxon: a web-based tool for the identification of prokaryotes based on 16S ribosomal RNA gene sequences. Int J Syst Evol Microbiol 57:2259-2261. https://doi. org/10.1099/ijs.0.64915-0

Ezaki T, Hashimoto Y, Yabuuchi E (1989) Fluorometric deoxyribonucleic acid-deoxyribonucleic acid hybridization in microdilution wells as an alternative to membrane filter hybridization in which radioisotopes are used to determine genetic relatedness among bacterial strains. Int J Syst Bacteriol 39:224-229

Feldgarden M, Brover V, Haft DH et al (2019) Validating the AMRFinder tool and resistance gene database by using antimicrobial resistance genotype-phenotype correlations in a collection of isolates. Antimicrob Agents Chemother 63(11):e00483-e519. https://doi.org/10.1128/aac.00483-19

Garcia-Fraile P, Velazquez E, Mateos PF, Martinez-Molina E, Rivas $\mathrm{R}$ (2008) Cohnella phaseoli sp. nov., isolated from root nodules of Phaseolus coccineus in Spain, and emended description of the genus Cohnella. Int J Syst and Evol Microbiol 58:1855-1859. https://doi.org/10.1099/ijs.0.65468-0

Hansen LH, Planellas MH, Long KS, Vester B (2012) The order Bacillales hosts functional homologs of the worrisome cfr antibiotic resistance gene. Antimicrob Agents Chemother 56:3563-3567. https://doi.org/10.1128/aac.00673-12

Hasegawa T, Takizawa M, Tanida S (1983) A rapid analysis for chemical grouping of aerobic actinomycetes. J Gen Appl Microbiol 29:319-322. https://doi.org/10.2323/jgam.29.319

Hiraishi A, Shin YK, Sugiyama J (1992) Rapid profiling of bacterial quinones by two dimensional thin-layer chromatography. Lett Appl Microbiol 14:170-173

Huerta-Cepas J, Szklarczyk D, Heller D et al (2019) eggNOG 5.0: a hierarchical functionally and phylogenetically annotated orthology resource based on 5090 organisms and 2502 viruses. Nucleic Acids Res 47:D309-D314. https://doi.org/10.1093/nar/gky1085

Kämpfer P, Rosselló-Mora R, Falsen E et al (2006) Cohnella thermotolerans gen. nov., sp. nov., and classification of 'Paenibacillus hongkongensis' as Cohnella hongkongensis sp. nov. Int J Syst Evol Microbiol 56:781-786. https://doi.org/10.1099/ijs.0.63985-0

Katoh K, Standley DM (2013) MAFFT multiple sequence alignment software version 7: improvements in performance and usability. Mol Biol Evol 30:772-780. https://doi.org/10.1093/molbev/ mst010

Khianngam S, Tanasupawat S, Akaracharanya A, Kim KK, Lee KC, Lee J-S (2012) Cohnella cellulosilytica sp. nov., isolated from buffalo faeces. Int J Syst Evol Microbiol 62:1921-1925. https:// doi.org/10.1099/ijs.0.032607-0

Kim S-J, Weon H-Y, Kim Y-S, Anandham R, Jeon Y-A, Hong S-B, Kwon S-W (2010) Cohnella yongneupensis sp. nov. and Cohnella ginsengisoli $\mathrm{sp}$. nov., isolated from two different soils. Int J Syst Evol Microbiol 60:526-530. https://doi.org/10.1099/ijs.0. 013581-0

Kim S-J, Weon H-Y, Kim Y-S, Kwon S-W (2011) Cohnella soli sp. nov. and Cohnella suwonensis sp. nov. isolated from soil samples in Korea. J Microbiol 49:1033-1038. https://doi.org/10.1007/ s12275-011-1071-8

Kumar S, Stecher G, Tamura K (2016) MEGA7: molecular evolutionary genetics analysis version 7.0 for bigger datasets. J Microbiol 33:1870-1874. https://doi.org/10.1093/molbev/msw054

Lane DJ (1991) 16S/23S rRNA sequencing. In: Stackebrandt E, Goodfellow M (eds) Nucleic acid techniques in bacterial systematics. Wiley, Chichester, pp 115-175

Lee I, Ouk Kim Y, Park S-C, Chun J (2016) OrthoANI: an improved algorithm and software for calculating average nucleotide identity. Int J Syst Evol Micr 66:1100-1103. https://doi.org/10.1099/ ijsem.0.000760

Liu B, Zheng D, Jin Q et al (2018) VFDB 2019: a comparative pathogenomic platform with an interactive web interface. Nucleic Acids Res 47:D687-D692. https://doi.org/10.1093/nar/gky1080

Meier-Kolthoff JP, Göker M (2019) TYGS is an automated highthroughput platform for state-of-the-art genome-based taxonomy. Nat Commun. https://doi.org/10.1038/s41467-019-10210-3

Meier-Kolthoff JP, Auch AF, Klenk H-P, Göker M (2013) Genome sequence-based species delimitation with confidence intervals and improved distance functions. BMC Bioinformatics 14:60. https:// doi.org/10.1186/1471-2105-14-60

Miller LT (1982) Single derivatization method for routine analysis of bacterial whole-cell fatty acid methyl esters including hydroxy acid. J Clin Microbiol 18:861-867

Minnikin DE, Hutchinson IG, Caldicott AB, Goodfellow M (1980) Thin layer chromatography of methanolysates of mycolic acid containing bacteria. J Chromatogr 188:221-233

Parte AC (2018) LPSN - List of prokaryotic names with standing in nomenclature (bacterio.net), 20 years on. Int J Syst Evol Micr 68:1825-1829. https://doi.org/10.1099/ijsem.0.002786

Ramasamy D, Mishra AK, Lagier J-C et al (2014) A polyphasic strategy incorporating genomic data for the taxonomic description of novel bacterial species. Int J Syst Evol Microbiol 64:384-391. https://doi.org/10.1099/ijs.0.057091-0

Seemann T (2014) Prokka: rapid prokaryotic genome annotation. Bioinformatics 30:2068-2069. https://doi.org/10.1093/bioinforma tics/btu153

Shiratori H, Tagami Y, Beppu T, Ueda K (2010) Cohnella fontinalis sp. nov., a xylanolytic bacterium isolated from fresh water. Int $\mathrm{J}$ Syst Evol Microbiol 60:1344-1348. https://doi.org/10.1099/ijs.0. 014605-0

Stamatakis A (2014) RAxML version 8: a tool for phylogenetic analysis and post-analysis of large phylogenies. Bioinformatics 30:1312-1313. https://doi.org/10.1093/bioinformatics/btu033

Tatusova T, DiCuccio M, Badretdin A et al (2016) NCBI prokaryotic genome annotation pipeline. Nucleic Acids Res 44:6614-6624. https://doi.org/10.1093/nar/gkw569

Zhu H-Z, Liu X-D, Jiang C-Y, Liu S-J (2019) Cohnella faecalis sp. nov., isolated from animal faeces in a karst cave. Int J Syst Evol Microbiol 69:572-577. https://doi.org/10.1099/ijsem.0.003228

Publisher's Note Springer Nature remains neutral with regard to jurisdictional claims in published maps and institutional affiliations. 